\title{
ANÁLISE MUSICAL NA PERSPECTIVA DE UMA FENOMENOLOGIA DA PERCEPÇÃO
}

\author{
Pedro Carneiro ${ }^{1}$
}

RESUMO: Do ponto de vista de uma fenomenologia da percepção, os vários modelos de análise, elaborados e trabalhados pela musicologia tradicional, apesar da aparente pluralidade e diversidade, não diferem tanto assim. De um modo geral, todos pressupõem um mesmo modo de se debruçar sobre a música. Por princípio, todos trabalham na perspectiva de uma postura analítica stricto sensu: dividir um problema em tantas partes quantas forem necessárias para melhor resolvê-lo. O que favorece um certo modo de 'escuta' comprometido apenas com a idéia de estrutura, escamoteando, portanto, a dimensão estética da experiência.

PALAVRAS-CHAVE: Análise; Estética; Fenomenologia; Musicologia.

ABSTRACT: From the point of view of a phenomenology of perception, the several analysis models elaborated and worked out by traditional musicology are not so different from each other, despite their plurality and diversity. Generally, all of them assume the same manner of studying music. In principle, all of them work in view of an analytical position, strictly speaking: dividing an issue into as many parts as 
necessary to better solve it. This favors a certain manner of 'perception' that is only dedicated to the idea of structure, thus concealing the aesthetic dimension of experience.

KEYWORDS: Analysis; Aesthetics; Phenomenology; Musicology. 
Sabemos, desde Husserl, que o trabalho do fenomenólogo consiste em permitir que as coisas se apresentem como elas são, livres de quaisquer construções intelectuais que, rotineiramente, projetamos nelas. Nessa perspectiva, no processo de experiência do conhecimento, não podemos, através de quadros teóricos de referencia, interferir nas coisas. São elas - as coisas - que se deixam revelar, que se mostram para nós. Aqui, não há ruptura entre o que é vivido e o que é pensado: o vivido e o pensado não são duas categorias separadas em planos diferentes. Ao contrario das atitudes racionalista e empirista, alicerçadas no pressuposto da dicotomia entre sujeito e objeto do conhecimento, a fenomenologia não faz distinção entre o papel atuante do sujeito cognoscente e a influência do objeto cognoscível. Merleau-Ponty observa que essas duas concepções (empirismo e racionalismo) estão impregnadas de construções artificiais acerca do fenômeno, com isso, nem uma nem outra é capaz de surpreender a consciência aprendendo, a dinâmica própria ao processo de conhecimento do conhecimento. $\mathrm{O}$ aprendizado da consciência ocorre no exercício do existir. Consciência e corpo dependem um do outro, funcionam em conjunto. Vivemos colados ao mundo exterior, portanto, o tradicional problema de se saber se o conhecimento parte das coisas para a consciência, ou da consciência para as coisas, não tem sentido para a fenomenologia, pois o objeto é sempre objeto para uma consciência e a consciência é sempre consciência de alguma coisa.

Tendo feito esses esclarecimentos introdutórios, passaremos a abordar algumas questões referentes ao exercício da análise musical. Jean-Jacques Nattiez, em seu artigo Semiologia musical e pedagogia da análise, celebra a recente diversidade de modelos de análise musical, 
segundo ele, até pouco tempo atrás, todo musicólogo quando desenvolvia um novo modelo de análise, descrição e explicação dos fatos musicais, comportava-se como se o recém criado, não apenas substituía os precedentes, como também os anulava. Prossegue ele, observando que o nosso momento atual é outro: "entramos numa nova fase da história da análise musical que nos obriga a admitir a coexistência dos diferentes modelos disponíveis" [NATTIEZ, 1990, p.50]. Em seguida, reporta-se a um "fenômeno novo e sintomático", que confirmaria esse novo momento para o campo da análise musical, a publicação em um curto período de tempo (entre 1985 e 1988) de cinco obras que apresentam e descrevem todos os modelos de análise, revelando não apenas "a pluralidade dos paradigmas acessíveis", mas o consenso em torno deles. Nattiez se refere às seguintes obras: o capítulo "Análise, teoria e música nova" do livro Musicologia de Joseph Kerman, publicado em 1985; o artigo “Análise" de Marc Devoto, publicado na edição do Harvard Dictionary of Music de 1986; a publicação, em 1987, em formato de livro de bolso, do artigo "Análise" de Ian Bent do New Grove Dictionary of Music and Musicians; o livro A Guide to Musical Analysis de Nicholas Cook, publicado em 1987 e o livro Music Analysis in Theory and Practice de Jonathan Dunsby e Arnold Whittall de1988.

Com base nessas obras, Nattiez elabora uma lista que classifica como sendo "as principais tendências" da análise musical do século XX. São elas:

A teoria da harmonia tonal de Henrich Schenker.

A abordagem da harmonia, da forma e do motivo, proposta por Arnold Schoenberg.

A proposta de análise do tema e do motivo segundo Rudolph Réti.

A "Set-Theory" desenvolvida por Allen Forte, com base nos estudos de Milton Babbitt para análise da música serial. 
A proposta de Leonard Meyer para análise rítmica e melódica.

O "Musical Critcism" desenvolvido por Joseph Kerman, Charles Rosen, Anthony Newcomp e Leo Treitler.

A Semiologia Musical de Nattiez e de Nicholas Ruwet.

As várias propostas de análise por computador.

A Teoria Generativa de Fred Lerdahl e Ray Jackendorrff, desenvolvida com base nos escritos do lingüista Noam Chomsky.

As análises musicais das várias tradições orais propostas pela etnomusicologia.

$\mathrm{Na}$ perspectiva da fenomenologia, tais modelos de análise, a partir do que nos apresentam, apesar da aparente pluralidade celebrada por Nattiez, não diferem tanto assim, todos pressupõem um certo modo de se debruçar sobre a música que, stricto sensu, é comum à todos: a postura analítica - dividir um problema em tantas partes quantas forem necessárias para melhor resolvê-lo - está no fundamento de todas as propostas apresentadas. Tal orientação teórica está na base de um certo entendimento da música, comprometido apenas com a idéia de estrutura, com isso, o trabalho do analista não vai muito além da identificação de características (padrões e regularidades) que são imanentes ao texto da partitura.

Observa-se, no âmbito desse modo de entendimento da música, uma certa paridade entre as noções de 'música' e 'estrutura', quando a música se reduz e se define por sua estrutura. Questões "exteriores", relativas ao processo composicional, ao contexto social que cerca o compositor, ou relativas ao ouvinte, à dimensão estética da experiência, ao gosto, à recepção pensada em um contexto sócio-histórico específico, não interessam 
ao analista, o foco recai apenas sobre o texto da partitura. Na lógica dessa dinâmica, música e partitura se confundem, se embaralham, parafraseando Umberto Eco (quando este se reporta a um texto de Jorge Luis Borges) é como se o mapa e o território fossem a mesma coisa, ou melhor, é como se o mapa fosse mais importante que o território [ECO, 1994, p.213].

Sobre isso, observa Joseph Kerman que os analistas padecem de uma certa miopia. A obstinada concentração destes nas relações internas é, na perspectiva de qualquer visão razoavelmente completa da música, em última instancia, subversiva. Entre os muitos elementos que contribuem para o significado e importância da música, a estrutura do texto da partitura é apenas um. O foco, quando limitado apenas à estrutura, negligencia questões e aspectos vitais - não só relativos a todo complexo histórico e social, mas igualmente à "tudo o que torna a música afetiva, tocante, emotiva e expressiva" [KERMAN, 1987, p.93].

Kerman chama nossa atenção para o fato de que a análise exerce forte influência sobre o modo como a teoria musical, enquanto uma matriz compreensiva da música (quando propõe e orienta acerca de como a música deve ser compreendida e pensada) é formulada. O campo da análise constitui - e institui - grande parte do que se conhece como teoria musical, "a teoria moderna não é (ou não é apenas) descritiva, mas, em certa medida, é também prescritiva" [KERMAN, 1987, p.94]. Talvez seja esta a maior miopia dos analistas, pretender traçar parâmetros para um modo singular de escuta musical em que a dimensão estética da experiência fica presa à questões que não ultrapassam os aspectos estruturantes relativos e limitados ao texto da partitura.

A idéia de uma estrutura autônoma, que separa a música do todo da vida, é algo que nos reporta ao século XIX de Edward Hanslick e à idéia de 'música pura' (de certo modo análoga à idéia 
de 'arte pela arte'). Para Hanslick, “a música compõe-se de série de sons, de formas sonoras; estas não têm outro conteúdo senão elas mesmas" [HANSLICK, 1987, p.155]. Talvez aqui se encontre o germe para o desenvolvimento de toda teoria musical moderna de matriz positivista. É o compromisso com o ideal de uma estrutura autônoma que nos torna míopes para as possibilidades de uma 'heteronomia' musical (no sentido de que não se limita às questões inerentes ao texto da partitura) possível de ser percebida no âmbito de uma fenomenologia da percepção musical.

O trabalho do analista, nestes termos, é procurar, identificar e classificar padrões e regularidades (melódicas, rítmicas, etc.) que caracterizariam e revelariam o ordenamento estrutural da partitura em estudo, ou seja, a identificação das invariantes estruturais responsáveis por sua singularidade e forma. O problema das invariantes estruturais - e a própria noção de estrutura não se separa de tais invariantes, atômicas ou relacionais - é fundamental para a lingüística. A esse respeito, Gilles Deleuze e Felix Guattari, problematizando, no âmbito da lingüística, acerca dessas questões, observam que é apenas sob essa condição que "a lingüística pode reivindicar para si uma pura cientificidade, nada a não ser ciência..., a salvo de qualquer fator supostamente exterior ou pragmático" [DELEUZE; GUATTARI, 1995, p.34].

O lingüista, quando preso à idéia das constantes estruturais, sejam elas fonológicas, morfológicas ou sintáticas, fecha a língua sobre si mesma, escamoteando, desse modo, as questões referentes ao âmbito da pragmática, ou seja, ao acontecimento de fato da língua, portanto, à dimensão de sua experiência - região da heteronomia.

Do mesmo modo, poder-se-ia dizer, que os analistas musicais (na esteira dos lingüistas), quando comprometidos 
com o ideal de uma musicologia científica, fecham a música sobre si própria. Ocorre que - retomando a fenomenologia - como nos lembra Merleau-Ponty, o modo como a ciência manipula as coisas, pressupõe a renúncia de habitá-las [MERLEAU-PONTY, 1975, p.275].

No terreno de uma fenomenologia da percepção musical, alimentada pela dinâmica do fato musical, tornase necessário "habitar" a música. Tarefa essa impensável quando se considera a postura do analista, sobretudo quando se postula um entendimento da música enquanto realidade autônoma. Porque comprometidos com o projeto de uma musicologia científica, os analistas preocupam-se apenas com as invariantes estruturais do texto da partitura, ignorando outras questões, referentes à 'pragmática musical', ou seja, ao acontecimento da música e à sua dimensão estética - irredutíveis ao método clássico de investigação científica. O método pede distanciamento, a música - no âmbito de seu acontecimento (situação pragmática) - pressupõe envolvimento.

No que diz respeito à necessidade de uma ênfase na dimensão pragmática - ou, se preferir à importância das esferas do 'performativo' e do 'ilocutório' - o que Deleuze e Guattari observam é a emergência de três importantes conseqüências: primeiro, a impossibilidade de pensarmos a linguagem como um código, observando que esta é a condição que possibilita uma explicação; e, igualmente, a impossibilidade de se pensar a fala como a comunicação de uma informação: considerando que ordenar, interrogar, prometer, afirmar, não se reduz à afirmação de um comando, uma dúvida, um compromisso, uma asserção, mas, de fato, consiste em efetuar esses atos imanentes específicos - necessariamente implícitos. 
Segundo, a impossibilidade de definição de uma semântica, uma sintaxe, uma fonética, enquanto campos científicos da linguagem, autônomos e independentes da dimensão pragmática; a pragmática deixa de ser uma problema, uma excrescência, as determinações do âmbito da pragmática deixam de estar submetidas à alternativa: "ou se voltar para o exterior da linguagem, ou responder às condições explícitas sob as quais elas são sintaxizadas e semantizadas" [DELEUZE; GUATTARI, 1995, p.14], ao contrario, a pragmática emerge como o pressuposto fundamental de todas as outras dimensões, manifesta-se e se insinua em toda parte.

Terceiro, a impossibilidade de assegurar a distinção entre língua e fala, considerando que a fala não pode mais ser definida, ou compreendida, simplesmente pela utilização extrínseca e individual de uma significação primeira, ou ainda, pela aplicação variável de uma sintaxe anterior: "ao contrario, são o sentido e a sintaxe da língua que não se deixam definir independentemente dos atos da fala que ela pressupõe" [DELEUZE; GUATTARI, 1995, p.14].

Ao fazerem tais reflexões, Deleuze e Guattari estão se reportando às teses de John L. Austin acerca dos aspectos performativos e ilocutórios da linguagem. O trabalho de Austin consiste em demonstrar que, muitas das relações que se estabelecem entre a fala e as ações que se realizam no ato da fala remetem-se mutuamente, na dinâmica de uma circularidade. É esse 'remeter-se mutuamente', porque intrínseco às circunstâncias próprias da enunciação, que define e qualifica o enunciado, melhor dizendo, na dinâmica dessa circularidade, enunciado e enunciação se confundem, poder-se-ia dizer que são a mesma coisa. Por exemplo, o performativo 'juro', ao dizer 'eu juro'. Como 
observa Deleuze e Guattari: "um enunciado performativo não é nada fora das circunstâncias que o tornam o que é. (...) 'Eu juro' não é o mesmo se for dito em família, na escola, em um amor, no interior de uma sociedade secreta, no tribunal" [DELEUZE; GUATTARI, 1995, p.20].

A ênfase na dimensão pragmática trás à tona questões relativas ao movimento da língua, aos aspectos que se mostram irredutíveis a uma gramática. No âmbito da dimensão pragmática, os problemas relativos à uma 'agramaticalidade' deixam de ser percebidos como contingência da fala — aquilo, de natureza exterior, que se oporia à ordem interna da gramática - para serem percebidos e compreendidos como uma característica própria da língua: algo que, estando em estado de variação contínua, atualizaria, permanentemente, um jogo de 'diferença e repetição', sempre alimentado e dinamizado pelas circunstâncias da enunciação. "A lingüística não é nada fora da pragmática (...) que define a efetuação da linguagem e o uso dos elementos da língua" [DELEUZE; GUATTARI, 1995, p.26].

No que diz respeito às questões relativas à análise musical, parafraseando Deleuze e Guattari, poderíamos dizer que: uma compreensão da música não existe independente de seu acontecimento - isto é, de sua situação pragmática - onde, igualmente, se verifica um jogo de 'diferença e repetição', que, permanentemente, atualiza o seu sentido, que, necessariamente, sempre emerge da situação e do modo em que a música é experienciada e vivida.

No âmbito da música (ou da arte), as questões relativas à dimensão pragmática (ou estética) abrange às questões referentes ao estilo. Retomando mais uma vez Deleuze e Guattari, eles observam que "o que denominamos um estilo, que pode ser a coisa mais natural do mundo, é precisamente o processo de uma variação contínua". Ora, entre todos 
os dualismos apresentados e instaurados pela lingüística, existem poucos com carência de fundamento como o que separa a lingüística da estilística: "sendo um estilo não uma criação psicológica individual, mas um agenciamento de enunciação, não será possível impedi-lo de fazer uma língua dentro de uma língua" [DELEUZE; GUATTARI, 1995, p.41].

Muito embora tais questões se refiram à lingüística, acreditamos que sua transposição para o âmbito da música (em particular no que se refere à produção e recepção estéticas) é de fundamental importância, sobretudo dentro de um projeto que se propõe pensá-la nos termos de sua dimensão pragmática, ou melhor, na dinâmica de uma fenomenologia da percepção musical.

As questões relativas ao estilo, tanto no âmbito da lingüística como no da arte, estão muito próximas. Maurice Merleau-Ponty, escrevendo sobre o trabalho do pintor, faz a seguinte consideração: "o que o pintor põe no quadro não é o eu imediato, o matizar-se do sentir, mas seu estilo, que conquista tanto por seus experimentos quanto pela pintura dos outros e do mundo" [MERLEAUPONTY, 1975, p.341]. Mas afinal, o que é o estilo? Como vimos, em Deleuze e Guattari é um procedimento de variação contínua, mas é, também, um agenciamento de enunciação. Ou seja, algo que se atualiza, que se enuncia, na dinâmica de um jogo de diferença e repetição. Esse jogo que se dá a partir dos processos de desterritorialização e reterritorialização de pressupostos estéticos estabelecidos, é percebido, nos termos de Merleau-Ponty, como algo que se desenvolve a partir dos experimentos do artista em relação à tradição - 'a pintura dos outros' - e o mundo. Dito de outro modo, a dinâmica própria do jogo de diferença e repetição, se desenvolve do conflito, ou, se 
preferir, do dialogo, entre o artista, a tradição e o mundo os envolve. O estilo emerge do modo (situação pragmática) como esse conflito, sempre alimentado pelos processos de desterritorialização e reterritorialização de valores, se resolve numa obra de arte acabada. Simplificando, poder-se-ia dizer que o estilo é algo que desdobra-se do modo como se joga.

Sobre isso, assinala Monclar Valverde que, em se concebendo a arte como um jogo, a criatividade artística surge como força resultante da tensão entre diferença $e$ repetição. Todo processo simbólico, todo processo através do qual se verifica a configuração de um sentido partilhado, "só é possível com o permanente confronto e combinação de padrões sistemáticos, regrados e estruturais, com um regime assistemático", envolvendo o acaso, a circunstância, a performance e o momento, que instaura e dinamiza a tensão entre diferença e repetição [VALVERDE, 2000, p.87].

Tendo feito tais considerações, podemos dizer que a obra dos compositores não pode ser reduzida à noção de um encadeamento de sons numa determinada estrutura. Por outro lado, o estilo não é, simplesmente, o resultado de uma vontade estética. Na esteira de Alfonso Quintás: os estilos resultam da confluência de diversos elementos - estéticos, éticos, religiosos, econômicos, políticos e sociais - que possibilitam e dão lugar a uma certa concepção de existência e a uma atitude vital correlativa [QUINTÁS, 1993, p.156].

Enquanto jogo, a arte revela e apresenta, como alternativa, um modo singular de estar no mundo, de responder e reagir às resistências que o mundo impõe, de ouvir ao chamado dos valores da cultura e da tradição, de ver e de viver o mundo no âmbito do registro das singularidades que instaura e oferece. Nesse sentido, é legítimo pensar que a obra dos compositores encarnam mundos particulares: o mundo de Bach, o mundo de Mozart, de Chopin, etc. [QUINTÁS, 1993, p.77]. 
Desde quando é plasmada e atualizada na dinâmica de um jogo, a arte não pode, ou não deveria, ser percebida e pensada nos termos de uma estrutura que se revela a partir de suas constantes e invariantes estruturais. Enquanto resultado e produto de um processo que representa a atualização de uma condição existencial, a arte constitui-se como uma espécie de possibilidade para um mundo - alternativo - possível e passível de ser habitado, experimentado, fruído, vivido, e, enquanto tal, é abertura de/para possibilidades transformadoras. Tal compreensão não é possível enquanto permanecemos condicionados a aquela noção de estrutura subjacente aos modelos de análise musical tradicionais.

$\mathrm{O}$ ato de compor pressupõe uma certa postura de abertura e disponibilidade para o todo da vida, melhor dizendo, abertura e disponibilidade para misturar o seu âmbito de realidade (ou, melhor, âmbito de vida) com o âmbito de outras realidades. Aqui, as noções de autonomia e heteronomia se confundem e coincidem, ambas conspiram em favor do jogo criativo. Nas palavras de Quintás: "essa atividade lúdica instaura vida espiritual, une o homem às realidades do meio ambiente com formas relevantes de unidade, põe-se na presença delas, porque supera a divisão entre o campo do interior e o do exterior. (...) A abertura à realidade sob o impulso dessa atitude concede ao homem liberdade interior, liberdade para a criatividade. (...) Esse modo elevado de liberdade (...) permite vincular de modo fecundo no homem a autonomia e a heteronomia, o poder de se governar por leis próprias, elaboradas em sua interioridade, e a necessidade de se orientar por critérios e normas recebidas em princípio de fora" [QUINTÁS, 1993, p.78].

O que é importante destacar do que foi colocado, é a percepção de que os 'mundos particulares', por exemplo, de 
Bach, Beethoven, ou Chopin, plasmados em suas obras, não são privativos destes. Como assinala Merleau-Ponty, em relação ao trabalho do pintor: "a obra não se passa longe das coisas e em algum laboratório íntimo cuja chave o pintor possuísse" [MERLEAU-PONTY, 1975, p.343]. A atitude de abertura e disponibilidade do artista, presente no jogo criativo, se estende até a obra. Os âmbitos de emoção da obra de arte, plasmados no âmbito do jogo entre a condição existencial do artista, as resistências do mundo e os valores da tradição, podem ser atualizados e vividos pelo fruidor. É, portanto, possível participar desse mundo - a obra de arte - de modo concreto, uma vez que pode ser habitado e partilhado.

Retomando mais uma vez Merleau-Ponty: "a obra que se cumpre não é, logo, a que existe em si como coisa, mas a que atinge o espectador, convidando-o a retomar o gesto que a criou e, saltando mediações, sem outro guia que não o movimento da linha inventada, a alcançar o mundo silencioso do pintor, ora proferido e acessível" [MERLEAU-PONTY, 1975, p.340].

Do que foi dito, gostaríamos de observar que, ao contrário de uma postura analítica que almeja a um entendimento objetivo da arte, que se pensa e se acredita autônoma do todo da vida; uma postura fenomenológica, alicerçada na experiência estética, pensa o fenômeno arte a partir do compromisso com uma participação ontológica entre obra de arte (enquanto jogo dinâmico que atualiza uma condição existencial) e o fruidor. No domínio dessa postura fenomenológica, tal modo de compreensão nos remete à etimologia da palavra 'conhecimento', no significado de 'nascer com'. Significado que, vale lembrar, atualmente só se mantém no francês: connaissance que é co-nascimento. 
Portanto, uma reflexão de natureza fenomenológica, que se desenvolve do âmbito da experiência estética, desdobra-se do envolvimento entre compositor e fruidor, ou seja, da possibilidade de uma participação de natureza ontológica que envolve os dois. Explica-se: tal participação é possível a partir da compreensão de que as obras dos compositores são abertas, ou seja, podem ser fruídas, pois encarnam mundos, que atualizam uma determinada condição existencial, plasmada no jogo da relação entre o compositor, os valores da tradição a qual pertence e as resistências do mundo (valores sociais, políticos, etc.) que o cerca. O resultado desse encontro (ou embate) entre o compositor e as realidades que o circunda, não pode ser reduzido (ou pensado) a um mero subjetivismo: o mundo impenetrável do compositor. Trata-se de uma entidade (desde o início) relacional, de um 'entre', que, por ser desse modo, possibilita a participação do outro. É nestes termos que a 'escuta', base para a experiência estética da música, que se desdobra do âmbito de uma participação ontológica entre compositor e fruidor, pode ser descrita e compreendida nos termos da 'lógica' de uma fenomenologia da percepção musical.

\section{NOTAS}

${ }^{1}$ Doutor em Comunicação e Semiótica pela PUC-SP com Pós-Doutorado pelo Departamento de Música da Escola de Comunicações e Artes da USP, atua como professor do curso de Música da Universidade Estadual de Feira de Santana-paoc@uefs.br. 


\section{REFERÊNCIAS}

DELEUZE, G.; GUATTARI, F. Mil Platôs, Capitalismo $e$ Esquizofrenia, Vol. 2. Rio de Janeiro: Editora 34, 1995.

ECO, U. Da impossibilidade de construir a carta do império em escala um por um. In: O Segundo Diário Mínimo, Rio de Janeiro: Editora Record, 1993.

HANSLICK, E. Do Belo Musical, Campinas: Editora da UNICAMP, 1989.

KERMAN, J. Musicologia, São Paulo: Martins Fontes, 1987.

MERLEAU-PONTY, M. O olho e o espírito. In: Textos escolhidos. São Paulo: Editora Abril, Col. Os Pensadores, Vol. XLI, 1975.

NATTIEZ, J. J. Semiologia musical e pedagogia da análise. In: Opus, Porto Alegre: UFRGS, No. 2, 1990, p.50-58.

QUINTÁS, A. L. Estética. Petrópolis: Editora Vozes, 1993.

VALVERDE, M. Estética e recepção. In: FAUSTO NETO, A. (Org.) Comunicação e Corporeidades. João Pessoa: Editora Universitária UFPB, 2000, p.87-100. 